\title{
GRAMÁTICA: APOIO OU OPRESSÃO?
}

\author{
GRAMMAR: SUPPORT OR OPPRESSION?
}

\begin{abstract}
Maria das Dores Aguiar Carvalho
RESUMO: Saber, gramática significa ser capaz de distinguir as expressões de uma língua, as categorias, as funções e as relações que entram em sua construção, descrevendo com elas sua estrutura interna e avaliando sua dramaticidade. Tudo isso é reflexo de um contexto sócio-históricoideológico, ou seja, de um modo de nossa sociedade ver os fatos em um determinado momento de sua história, que regula e afeta o uso da linguagem, mudando isto, mudará o texto e sua construção dentro de uma variedade da língua e o efeito de sentido que ele poderá produzir.
\end{abstract}

Palavras - chave: Gramática. Estrutura Interna. Gramaticidade. Contexto Sócio - HistóricoIdeológico.

ABSTRACT: Nowing, grammatic means being able to distinguish the expressions of a language, the categories, the functions and the relationships that enter in its construction, describing with them its internal structure and assessing its grammaticity. All this is a reflection of a socio-historyideological context, that is, of a way of our society viewing the facts in a certain moment of its history, that regulates and affects the use of language, changing this, will change your text construction within a variety of language and the effect of sense that it can produce.

Keywords: Grammar. Internal Structure. Grammarity. Social Context. Historical-Ideological.

\section{INTRODUÇÃO}

O ensino da gramática é abordado nas escolas, desde as séries iniciais, e é quase unânime o medo que essa disciplina causa em nossos educandos. Isso acontece, infelizmente, em muitos casos porque nós como professores queremos impor aos nossos educandos as normas gramaticais e desejamos que estes aprendam porque nós assim o queremos. Nem ao menos, explicamos aos alunos o porquê do aprender gramática. Existe ainda o fato de queremos que os discentes aprendam as regras

\footnotetext{
${ }^{1}$ Formada em Letras pela Universidade Estadual do Maranhão; Tem especialização em Docência do Ensino Superior e Planejamento Educacional (pela Universidade Aberta do Brasil) e é Especialista em Educação Inclusiva ( pela Universidade Católica Dom Bosco) e atua como Professora de Língua Portuguesa da rede Estadual e Municipal no município de São Bento- MA, desde 1997. E- mail: r2dorinha.carvalho@gmail.com.
} 
gramaticais dissociadas do texto e do contexto. Sem dúvida, vai ser uma tarefa difícil, para não dizer impossível. Pois ensinar gramática sem contextualizar é impossível. Sendo assim, neste artigo abordaremos algumas concepções de gramática e suas principais funções.

Se a nossa questão é o ensino de gramática é necessário dizer ainda o que entendemos por gramática e, de acordo com cada concepção, o que seria saber gramática e o que é ser gramatical. Deter-nos-emos aqui, em apenas três das muitas concepções que envolve esse vocábulo.

$\mathrm{Na}$ primeira concepção vemos a gramática concebida como um manual com regras de bom uso da língua a serem seguidas por aqueles que querem se expressar adequadamente. Essa concepção é normalmente rotulada de Gramática normativa. Segundo a qual a gramática é um conjunto sistemático de normas para bem falar e escrever. Regras essas estabelecidas pelos especialistas. Portanto dizer que alguém sabe gramática, significa dizer que esse alguém conhece essas normas e as domina.

Como afirma Morais (2008, p.126):

Ancoradas numa gramática normativa insensível ao modo como as pessoas realmente falam e escrevem, as didáticas da língua portuguesa que até hoje encontramos em muitas escolas levam o aprendiz a ver as atividades de ler e escrever como coisas estranhas a ele.

Nesse primeiro sentido, afirma-se que a língua é só a variedade dita padrão ou culta e que todas as outras formas de uso da língua são desvios, erros, deformações, degenerações linguísticas e que, por isso a variedade considerada "padrão" deve ser seguida por todos os cidadãos falantes dessa língua para não contribuir com a degeneração linguística de seu país.

Assim essa gramática só trata da variedade de língua que se considerou norma culta, fazendo uma descrição dessa variedade e considerando erro tudo o que não está de acordo com o que é usado nessa variedade da língua, ou seja, tudo o que foge a esse padrão é errado ( agramatical , ou melhor ,não - gramatical) e o que atende a esses requisitos é certo (gramatical).

Sobre essa problemática, o PCN de Língua Portuguesa (pág. 33.] Diz que:

As práticas de linguagem são uma totalidade; não podem, na escola, ser apresentadas de maneira fragmentada, sob pena de não se tornarem reconhecíveis e de terem sua aprendizagem inviabilizada. Ainda que didaticamente seja necessário realizar recortes e descolamentos para melhor compreender o funcionamento da linguagem, é fato que a observação e análise de um aspecto demandam o exercício constante de articulação com os demais aspectos envolvidos 
no processo. Ao invés de organizar o ensino em unidades formatadas em texto, tópicos de gramática e redação, fechadas em si mesmas de maneira desarticulada, as atividades propostas no ambiente escolar devem considerar as especificidades de cada uma das práticas de linguagem em função da articulação que estabelecem entre si.

Bagno (2003) salienta que:

Portanto essa língua que querem nos impingir a falar não é uma língua conhecida e praticada pelos brasileiros, mas uma língua totalmente diferente. É como se tivesse que aprender uma língua nova como o inglês ou francês. Ademais tenta-se impor uma gramática que nada tem a ver com a gramática intuitiva do falante. Bagno (2003, p. 36)

Sabe-se que essas normas de bom uso da língua são baseadas no uso consagrado pelos bons escritores e, portanto, ignoram as características próprias da linguagem oral. Além disso, ignorando e depreciando outras variedades da língua com base em fatores não estreitamente linguísticos ,criam preconceitos linguísticos,por baseia-se em padrões, muitas vezes equivocados ,tais como : purismo e vernaculidade, classe social de prestígio( de natureza econômica , política ou cultural),autoridade ( gramáticos, bons escritores), lógica e histórica( tradição).Como vemos, estão embutidos nessa concepção de gramática vários modos de perceber e definir a chamada norma culta ou excluir dela formas e usos ,e assim, fundamentar e defender seu papel prescritivo.

Travaglia (2003) aponta que a gramática da língua portuguesa sempre foi vista historicamente como a gramática normativa, isto é, aquela que corresponde às formas de expressão produzidas por pessoas cultas. Nesse aspecto, segundo o autor, o ensino de língua portuguesa nas escolas brasileiras, tradicionalmente, veio sendo baseado na concepção de aplicação das normas ditadas pela gramática da língua culta e amparado nos renomados autores de textos literário.

A segunda concepção de gramática da qual iremos falar é a que tem sido chamada de "gramática descritiva", pois verdadeiramente faz uma descrição da estrutura e funcionamento da língua, de sua forma e função. Segundo essa concepção, gramática seria um conjunto de regras que o cientista encontra nos dados que analisa, à luz de determinada teoria e método. Essas regras seriam as utilizadas pelos falantes na construção real de enunciados. Gramática nessa concepção, é um sistema de noções diante as quais se descrevem os fatos de uma língua, permitindo associar a cada expressão dessa língua uma descrição estrutural e estabelecer suas regras de uso, de modo a separar 
o que é gramatical do que não é gramatical. Gramatical será, então, tudo o que atende as regras de funcionamento da língua de acordo com determinada variedade linguística. $O$ critério é propriamente linguístico e objetivo, pois não se diz que não pertencem à língua formas e usos presentes no dizer dos usuários desta e aceita por estes como próprias da língua que estão usando.

São representantes dessa concepção as gramáticas feitas de acordo com as teorias estruturalistas que privilegiam a descrição da língua oral e as gramáticas feitas segundo a teoria gerativa-transformacional que trabalha com enunciados ideais, ou seja, produzida por falanteouvinte-ideal. As correntes linguísticas que dão base a esse tipo de gramática têm em comum o fato de proporem uma homogeneidade do sistema linguístico, abstraindo a língua de seu contexto, ou seja, elas trabalham com um sistema formal abstrato que regula o uso que se tem em cada variedade linguística.

Vieira e Brandão (2007, p.I5) classificam a gramática descritiva como sendo aquela que "pretende depreender o sistema de uma língua, através do estabelecimento de unidades no interior de cada sistema e de suas relações opositivas", ou seja, a língua deve ser estudada como ela é e não somente através de sua estrutura, deve ser vista de forma heterogênea tanto na fala quanto na escrita, sem descartar, mas adaptando, as regras de uso.

Possenti (2003, p. 66) fala que

O gramatico descritivista não está preocupado em mostrar erros, mas pode ir além da constatação de que existem, verificando, por exemplo, que elas são utilizadas por pessoas de diferentes grupos sociais.

Neste e terceiro e último critério a ser analisado, neste trabalho, deter-nos-emos falando um pouco sobre a concepção segundo a qual a gramática é um conjunto de variedades linguísticas utilizadas por uma sociedade de acordo com o exigido pela situação de interação comunicativa em que o usuário da língua está engajado. Esta concepção percebe a gramática como um conjunto de regras que o falante de fato aprendeu e das quais lança mão ao falar. Portanto, correspondendo ao saber linguístico que o falante da língua desenvolve dentro de certos limites impostos pela sua própria dotação genética humana e em condições apropriadas de natureza social e antropológica.

Nesse sentido, saber gramática não depende, pois, a princípio de escolarização, ou de quaisquer processos de aprendizado sistemático, mas da ativação e amadurecimento progressivo (ou 
da construção progressiva), na própria atividade linguística, de hipóteses sobre o que seja a linguagem e seus princípios e regras. Nessa concepção não existe gramáticas, pois esta é o objeto da descrição. Daí porque normalmente essa gramática seja chamada de gramática internalizada, ou seja, a gramática nata do falante.

PERINI (1997 P.13) ventila que "qualquer falante da língua portuguesa possui uma gramática internalizada, altamente elaborado da língua, muito embora não saiba explicitar”.

\section{CONSIDERAÇÕES FINAIS}

Depois destes rápidos comentários, chegamos a conclusão de que não há contradição de base entre os teóricos dessas concepções, o que existe é diferença de enfoque e de grau de limitação. No entanto, temos consciência de que, ao escrevermos não deveremos ficar "obstinados" em demonstrar erudição e cultura gramatical, pois se desejarmos escrever bem, deveremos dirigir a nossa preocupação para as três funções básicas da comunicação: produzir respostas, tornar comum e persuadir. Uma vez que no ensino de gramática não existe Pedagogia, Psicologia, Fonoaudiologia, e tantas mais "gias" as quais você possa imaginar, que substitua o conhecimento linguístico que o professor deve ter. Nota-se, portanto, que há sim uma necessidade de se ensinar gramática, mas de forma alguma poderemos desconsiderar a gramática internalizada que existe em cada discente, para que este venha compreender a gramática normativa como forma de apoio e não como forma de opressão.

Mendonça (2006) diz:

[...] ao optar por uma ou outra corrente teórica, por esta e não aquela metodologia, valores e crenças são acionados, uma vez que a identidade profissional de quem ensina é posta em xeque e, por consequência, o valor que se atribui ao seu trabalho. O ensino de gramática tem relação direta com as identidades construídas no interior da escola e fora dela: o que é importante ensinar, o que faz um bom professor de português, como deve ser a aula de português, o que deve se avaliar e como etc. Interligam-se, inevitavelmente, concep̧̧ões teóricas, sejam elas conscientes ou não, e escolhas metodológicas.

Sendo assim, precisamos aceitar os conhecimentos internalizados que os nossos educandos trazem consigo para que as aulas de Língua Portuguesa se tornem prazerosas, possibilitando assim uma aprendizagem eficaz; e isso só irá acontecer quando os discentes sentirem-se parte fundamental desse processo e não meros expectadores. 


\section{REFERÊNCIAS}

BAGNO, Marcos. Preconceito linguístico: o que é, como se faz. São Paulo: Loyola, 2003.

BRASIL. Secretaria de Educação Fundamental. Parâmetros curriculares nacionais: língua portuguesa/ Secretaria de Educação Fundamental. Brasília. 1997.

MENDONÇA, Márcia. Análise Linguística no Ensino Médio: Um Novo Olhar, Um Outro Objeto. In Clécio Bunzen (org). Português no Ensino Médio e Formação do Professor. I $^{\underline{a}}$ Ed.

MORAIS, Artur Gomes de. Ortografia: Ensinar e Aprender. 4. ed. São Paulo: Editora Ática, 2008. PERINI ,Mário A.Sofrendo a gramática .São Paulo .Editora Ática,1997

POSSENTI,sírio. Porque (não) ensinar gramática na escola.São Paulo.Mercado de Letras,2003

TRAVAGLIA, Luiz Carlos. Gramática e interação: uma proposta para o ensino da gramática no $\mathbf{I}^{\circ}$ e 2o grau.I Edição. São Paulo: Cortez,2002.

Gramática: ensino plural. São Paulo: Cortez,2004.

VIEIRA, Silvia Rodrigues. BRANDÃO, Silvia Figueiredo. Ensino de gramática: descrição e uso. São Paulo. Contexto, 2007.

VIGOTSKY, L. S. Pensamento e Linguagem. São Paulo: Martins Fontes. São Paulo: Parábola, 2006, p. $199-226$ 